\title{
Carboxyl terminus of Hsp70-interacting protein (CHIP) is required to modulate cardiac hypertrophy and attenuate autophagy during exercise
}

\author{
Monte S. Willis ${ }^{1,2,{ }^{*}, \text { Jin-Na Min }}{ }^{1,}$, Shaobin Wang ${ }^{1}$, Holly McDonough ${ }^{1}$, Pamela Lockyer ${ }^{1,2}$, \\ Kristine M. Wadosky², and Cam Patterson ${ }^{1,3,4}$ \\ ${ }^{1}$ McAllister Heart Institute, University of North Carolina, Chapel Hill, NC \\ ${ }^{2}$ Department of Pathology and Laboratory Medicine, University of North Carolina, Chapel Hill, NC \\ ${ }^{3}$ Departments of Cell and Developmental Biology, University of North Carolina, Chapel Hill, NC \\ ${ }^{4}$ Departments of Medicine and Pharmacology, University of North Carolina, Chapel Hill, NC
}

\section{Abstract}

The carboxyl terminus of HSP70-interacting protein (CHIP) is a ubiquitin ligase/co-chaperone critical for the maintenance of cardiac function. Mice lacking CHIP (CHIP -/-) suffer decreased survival, enhanced myocardial injury, and increased arrhythmias compared to wild type controls following challenge with cardiac ischemia reperfusion injury. Recent evidence implicates a role for CHIP in chaperone-assisted selective autophagy, a process that is associated with exerciseinduced cardioprotection. To determine whether CHIP is involved in cardiac autophagy, we challenged CHIP -/- mice with voluntary exercise. CHIP -/- mice respond to exercise with an enhanced autophagic response that is associated with an exaggerated cardiac hypertrophy phenotype. No impairment of function was identified in the CHIP -/- mice by serial echocardiography over the five weeks of running, indicating that the cardiac hypertrophy was physiologic not pathologic in nature. It was further determined that CHIP plays a role in inhibiting Akt signaling and autophagy determined by autophagic flux in cardiomyocytes and in the intact heart. Taken together, cardiac CHIP appears to play a role in regulating autophagy during the development of cardiac hypertrophy, possibly by its role in supporting Akt signaling, induced by voluntary running in vivo.

\section{Keywords}

ubiquitin ligase; CHIP; heart; cardiac hypertrophy; IGF-1 signaling; autophagy

\section{Introduction}

The carboxyl terminus of Hsp70-interacting protein (CHIP) is a ubiquitin ligase/cochaperone that is critical for the maintenance of cardiac function, largely through its influence on protein quality control pathways. CHIP regulates protein quality control in 2 distinct ways. First, CHIP binds to protein substrates to mediate their refolding though its co-chaperone activity and interaction with the heat shock protein Hsp70 1,2. Second, CHIP recognizes, ubiquitinates, and degrades unfolded chaperone substrates as a U-box-dependent

Address correspondence and inquiries to: Cam Patterson, M.D., M.B.A., Director, Division of Cardiology and UNC, McAllister Heart Institute, University of North Carolina at Chapel Hill, 8200 Medical Biomolecular Research Building, Chapel Hill, North Carolina 27599-7126, Tel.: (919) 843-6477, Fax: (919) 843-4585, cpatters@ med.unc.edu.

Contributed equally 
ubiquitin ligase and co-chaperone/chaperone ${ }^{3-6}$. The importance of CHIP's function as a regulator of cardiac protein quality control is illustrated by the fact that CHIP $-/-$ mice are unable to withstand the cardiac challenge brought about by ischemia/reperfusion (I/R) injury, suffering decreased survival and an increase in arrhythmias and myocardial injury ${ }^{7}$.

Recently, CHIP's involvement in the maintenance of protein quality control has been extended to include the process of autophagy ${ }^{8}$. In both Drosophila and mouse striated muscle, CHIP colocalizes with the cochaperone molecule BAG-3 (Starvin in Drosophila cells) in a multiprotein complex situated at the Z-disc and facilitates the ubiquitin-dependent autophagic degradation of the sarcomeric protein filamin ${ }^{8}$. This process of autophagy has been termed chaperone-assisted selective autophagy (CASA) to distinguish it from the related process of chaperone-mediated autophagy, which involves the ubiquitin-independent translocation of a target substrate across the lysosomal membrane ${ }^{9}$.

In the heart, autophagy is an integral component of the molecular mechanisms involved in regulating cardiac protein quality control. Autophagy of cardiac proteins is associated with exercise-induced cardioprotection ${ }^{1011}$ and with the remodeling response to cardiac hypertrophy and other stressors (see recent reviews ${ }^{12,13}$ ). These stressors, such as I/R injury, can regulate the amount of autophagy within the cell, which in turn can determine a cell's susceptibility to damage. For example, autophagic flux through the macroautophagy pathway, a measure of autophagosome clearance, is markedly impaired with reperfusion (reoxygenation) after an ischemic (hypoxic) insult ${ }^{14}$. Autophagy impairment may contribute to I/R-induced cardiomyocyte cell death by failing to clear damaged mitochondria and misfolded proteins formed in response to enhanced oxidative stress ${ }^{15}$. When preconditioning against $\mathrm{I} / \mathrm{R}$, the challenge of a brief ischemia to induce subsequent protection against I/R injury, autophagy has been found to be essential for cardioprotection and related to its regulation of mitochondrial permeability pore ${ }^{16,17}$. Enhancing autophagy protects against I/R injury ${ }^{18}$ through its enhanced turnover of damaged mitochondria by ubiquitin ligases such as Parkin and the autophagic adapter protein p62, which directly translocates to mitochondria to mediate this clearance ${ }^{19}$. Others have hypothesized that misfolded proteins accumulating in I/R injury are cleared by autophagy and prevent an accelerated heart failure by preventing protein aggregate proteotoxicity (cell death) ${ }^{12,20,21}$. The enhanced removal of ROS-producing mitochondria by autophagy can also decrease the oxidative stress experienced by a cell; this explains how caloric restriction, which potently induces autophagy, is associated with less damage when challenged with oxidative stress ${ }^{22}$. These multiple lines of evidence link the ubiquitin proteasome system with the autophagic clearance of mitochondria and misfolded proteins, resulting in enhanced cellular performance in the face of oxidative stress.

It is already well-documented that the ubiquitin ligase CHIP plays a critical role in maintaining cardiac structure and function during times of stress, prompted us to examine whether CHIP is involved in autophagic protein degradation in the heart. To examine this, we used voluntary unloaded wheel running, an established model of physiologic cardiac hypertrophy ${ }^{23-25}$, to determine whether cardiac autophagy could be induced as it is in other muscles in response to exercise ${ }^{26-28}$. We found that hearts from CHIP $-/-$ mice respond to voluntary exercise with an enhanced autophagic response that is associated with an exaggerated hypertrophic phenotype. We further determined that CHIP plays a role in regulating Akt signaling in cardiomyocytes. These findings implicate for the first time a role for cardiac CHIP in regulating the autophagic response and the involvement of Akt in physiologic cardiac hypertrophy. 


\section{Materials and Methods}

\section{Animals and histology}

CHIP -/- mice were generated and maintained on a mixed genetic background of C57/BL6 and $129 \mathrm{SvEv}{ }^{29}$. Mice in the present study were 24 weeks of age at the beginning of the study. Mice were euthanized after 5 weeks of wheel running exercise (or sham exercise, described below) and hearts were processed in one of two ways: 1) fixed in $4 \%$ paraformaldehyde, processed for paraffin embedding, and subsequently sectioned and stained with standard hematoxylin and eosin (H\&E) and Masson's Trichrome; or 2) fixed in a freshly prepared solution of $2 \%$ paraformaldehyde $2.5 \%$ glutaraldehyde in $0.15 \mathrm{M}$ sodium phosphate buffer, $\mathrm{pH} 7.4$, processed for electron microscopy and imaged using a LEO EM910 transmission electron microscopy at $80 \mathrm{kV}$ (LEO Electron Microscopy Ltd.. Images of transmission electron micrographs were obtained using a Gatan Bioscan Digital Camera (Gatan, Inc.). H\&E and Masson's Trichrome stained slides were scanned using an Aperio Scancope and exported using Aperio Imagescope software (Version 10.0.36.1805, Aperio Technologies, Inc.). All animal husbandry and experiments were approved by the institutional care and use committee (IACUC) for animal research at the University of North Carolina at Chapel Hill.

\section{Measuring cross sectional area of cardiomyocytes}

Paraffin embedded heart sections were stained with a TRITC-labeled lectin as previously described ${ }^{30}$. Cardiomyocyte cross sectional area was measured using Image $\mathbf{J}$ software. A minimum of 20 random fields at 200 x magnification in the left ventricle were imaged from at least 3 different hearts. A minimum of 100 cardiomyocytes per heart were measured for calculating the average of cross sectional area.

\section{Unloaded voluntary wheel exercise-induced cardiac hypertrophy}

A voluntary, unloaded wheel exercise challenge was used to induce physiologic hypertrophy in female mice as previously described ${ }^{31}$. Briefly, mice were assigned to either unloaded (no-resistance) wheel running $(\mathrm{N}=16)$ or sedentary control groups $(\mathrm{N}=16)$. Wild-type littermates were similarly assigned to either unloaded wheel running or sedentary control groups ( $\mathrm{N}=14$ per group). Exercise wheel use was monitored using a Mity 8 Cyclocomputer (model CC-MT400), recording distance, average speed, maximum speed, and running time. Running statistics were recorded daily. Only mice with completed data sets were included in the running statistics shown in Supplemental Figure 1A. Hearts were morphometrically analyzed by echocardiography at baseline before voluntarily exercise was initiated and after 5 weeks of exercise, as previously described ${ }^{32}$. Mice were sacrificed via isoflurane inhalation overdose and subsequent cervical dislocation before organs were harvested for further analysis.

\section{Echocardiography}

Cardiac trans-thoracic echocardiography was performed on conscious mice using a VisualSonics Vevo 770 ultrasound biomicroscopy system (VisualSonics, Inc.) using the 707B scan head (30 MHz; blinded to mouse genotype and treatment) as previously described ${ }^{33,34}$. Two-dimensional guided M-mode was performed in the parasternal longaxis and short-axis at the level of the papillary muscle. Epicardial to endocardial leading edges were used to measure anterior and posterior wall thicknesses and left ventricular internal diameters. Left ventricular systolic function was assessed by ejection fraction (LV $\mathrm{EF} \%=[(\mathrm{LV}$ Vol; d-LV Vol;s/LV Vol;d)*100] and fractional shortening (\%FS=[(LVEDDLVESD)/LVEDD] $\times 100$ ). M-mode measurements represent 3 average consecutive cardiac cycles from each mouse. 


\section{In vitro studies}

The cardiac-derived HL-1 cell line was used to create stably transduced cell lines with CHIP knockdown using lentivirus shRNA. Briefly, HL-1 cells ${ }^{35}$ were treated with lentivirus expressing CHIP shRNA (lentiviral vectors were obtained from Open Biosystems, CHIP shRNA, Cat.\#s TRCN0000008528, TRCN0000008527 and TRCN0000008530; empty vector pLKO1, Cat.\#RHS4080) to knock-down CHIP. After 24 hours, cells were selected with puromycin $(3 \mathrm{ug} / \mathrm{ml})$ for $48 \mathrm{hr}$, a time point where all control cells had died. The surviving cells were then expanded and stored in liquid nitrogen with freezing media. Cells were cultured in serum free DMEM for 16 hours prior to experiments, then treated with 10 ng/ml IGF-1 (Cat.\#I1146, Sigma-Aldrich, St. Louis, MO) for 30 minutes or 4 hours, harvested and prepared for Western blot analysis.

\section{Immunoblotting and real-time PCR analysis}

Heart tissue was snap frozen in liquid nitrogen, homogenized in RIPA buffer and centrifuged at $14,000 \times \mathrm{g}$ for 15 minutes at $4 \mathrm{C}$ to remove cell debris. Protein concentration of the supernatant was determined using a BCA assay (Thermo Fisher Scientific, Inc.). Thirty to fifty $\mu \mathrm{g}$ of protein was loaded onto PAGE, transferred to PVDF membranes and immunoblotted. Membranes were blocked in $3 \%$ skim milk in $1 \times$ PBS, incubated with primary antibody (1:2000 dilution in blocking buffer, unless otherwise indicated) overnight at $4 \mathrm{C}$ and incubated with HRP-conjugated secondary antibody (1:10,000 dilution in blocking buffer) for 1 hour at room temperature before being processed using the ECL detection system (Amersham ECL Plus ${ }^{\mathrm{TM}}$ Western Blotting Detection Reagents). Primary antibodies for AKT (Cat.\#9272), pAKT(S473) (Cat.\#9271), pGSK3a(S21) (Cat.\#9316), and anti-pGSK33(S9) (Cat.\#9336), and LC3B (Cat.\#3868) were purchased from Cell Signaling Technology, Inc. Antibodies recognizing LC3B (Cat.\#L7543, 1:500) in tissue, GAPDH (Cat.\#G8795, 1:4000), and $\beta$-tubulin (Cat.\#T8328, 1:4000) were purchased from SigmaAldrich. Antibody recognizing total GSK3 (Cat.\#44-610) was purchased from Invitrogen, Inc. Antibodies specific for CHIP (Millipore, Cat.\#AB10000) were used in Western blot analysis. For real-time PCR analysis, total RNA from hearts was extracted using Trizol (Invitrogen Corporation, Cat.\#15596-026) solution. cDNA was synthesized using GoScript reverse transcription kit (Promega Corporation, Cat.\#A5000) and primer pairs for real-time PCR were designed using Roche Applied Science Universal Probe Library Web (https:// www.roche-applied-science.com/sis/rtpcr/upl/index.jsp?id=uplct_000000). The specific primers and probes from the mouse Universal ProbeLibrary Set, (Roche) are detailed in Supplemental Table 1. $\beta$-MHC mRNA expression was determined using the Mm00600555_m1 TaqMan Probe (Applied Biosystems). All qRT-PCR results were normalized to 18S (TaqMan Probe, Hs99999901_s1) mRNA expression.

\section{Determination of autophagic flux both in vitro and in vivo}

Autophagic flux was determined in vivo based on the titration of bafilomycin A1 doses over time to optimize animal survival without eliciting any other major dysfunction, while effectively inhibiting autophagy as previously described 36,37 . Briefly, stock bafilomycin A1 (BFA, cat\# sc-201550A, Santa Cruz Biotechnology, Santa Cruz, CA)(3 mM stock in DMSO) was diluted in PBS (40\% DMSO final). Mice were then treated with this dilution to a final of $3 \mu \mathrm{mol} / \mathrm{kg}$ by intraperitoneal injection (in $\sim 200 \mu \mathrm{l}$ total). One hour later, a second equivalent injection was given. Mice were euthanized and tissues collected for further analysis by Western immunoblot for LC3B isoforms one hour after the second injection. To determine autophagic flux in vitro, cells were treated with $100 \mathrm{nM}$ bafilomycin A1 2 hours prior to harvest. 


\section{Statistics}

A Student's t-test (GraphPad Prism 5) was performed on all compared values to obtain statistical significance or ANOVA with Holm-Sidak pairwise post hoc analysis (Sigma Stat 3.5). Significance was defined as a p value less than 0.05 .

\section{Results \\ CHIP-/- mice display increased markers of cardiac autophagy following voluntary exercise}

CHIP has a number of cellular functions, including supporting protein refolding through its interactions with heat shock proteins (Hsp70/BAG2), and also degrading proteins by its ubiquitin ligase activity ${ }^{38,39}$. CHIP's role in protein quality control has recently been shown to be even more diverse by the discovery that CHIP can be involved in the process of autophagy ${ }^{8,40}$. Specifically, these studies have identified that the HSPB8/BAG3/HSC70/ CHIP multi-heteromeric complex selectively activates autophagic removal of misfolded proteins in Drosophila muscle and mouse systems ${ }^{8,40}$. Since autophagy is now appreciated as a factor involved in the development of a variety of cardiac stressors, including hypertrophy ${ }^{12,41}$, we decided to investigate the autophagic activity in hearts from CHIP -/mice following 5 weeks of voluntary running.

Cardiac autophagy was evaluated by measuring the expression of autophagic-associated genes, transmission electron microscopy, and by autophagic flux in sham and running CHIP -/- and wildtype control mice. RT-PCR analysis of CHIP -/- hearts identified increases in autophagy-related genes GabarapL1, Atg7, Atg5, Vps34, and Bnip3 after 5 weeks of running (Figure 1A, right), suggesting that increased autophagic activity may be present in CHIP -/hearts after voluntary running. Transmission electron microscopy analysis of tissue sections from hearts of CHIP -/- running mice revealed increases the presence of membrane bound autophagosomes/autolysosomes containing mitochondrial cellular material indicative of autophagy (Figure 1B). These structural changes were not seen in sections taken from hearts of CHIP $-/-$ mice in the sham CHIP $-/-$ mice or in hearts isolated from sham or running wildtype mice. After one week of running, autophagic flux in the heart measured by LC3BII expression after bafilomycin treatment indicated an enhanced autophagic response in CHIP -/- mice compared to wild type controls (Figure 2A vs. steady state LC3B levels Supplemental Figure 1B). Taken together, the real time analysis of genes involved in autophagy, the TEM identification of mitochondria in vesicles, and an increase in autophagic flux demonstrate that voluntary exercise stimulates autophagic activity in the hearts of CHIP -/- mice, but not wild-type mice, suggesting that CHIP is involved in attenuating cardiac autophagy due to increased cardiac demand.

Chaperone-mediated autophagy occurs during conditions of cellular stress and is responsible for degrading $\sim 30 \%$ of cytosolic proteins ${ }^{42,43}$. Substrates for this degradative pathway contain a pentapeptide motif (KFERQ) that is selectively recognized by the heat shock cognate protein of $70 \mathrm{kDa}(\mathrm{Hsc} 70)^{44}$. When substrates interact with the chaperone, it targets the complex to the lysosomal membrane where it binds the protein LAMP2A ${ }^{45}$. Since LAMP2A (lysosomal membrane bound lysosomal-associated membrane protein $2 \mathrm{~A}$ ) is increased during chaperone-mediated autophagy ${ }^{46,47}$, we used real time PCR to investigate the expression of $L A M P 2 A$ and the lysosomal Cathepsin $L$ in the hearts from CHIP $-/-$ mice after 5 weeks of voluntary running (Figure 2B). We found that hearts from CHIP $-/-$ mice that had undergone 5 weeks of voluntary exercise, but not wild-type mice from the running group, had an $\sim 2.4$ fold increase in $L A M P 2 A$ and an $\sim 3.2$ fold increase in Cathepsin $L$ compared to mice of either genotype from the control group. The increase in both $L A M P 2 A$ and Cathepsin L during exercise in the CHIP-deficient hearts is consistent with the data 
collected from RT-PCR, TEM, and autophagic flux studies indicating the presence of enhanced autophagic activity, a process that is not active in the hearts from wild-type mice voluntarily running.

\section{Cardiac CHIP modulates cardiomyocyte size in voluntary exercise}

Voluntary running in wild-type mice induced cardiac hypertrophy as determined by a $28.8 \%$ increase in heart weight/body weight (HW/BW; 5.33 vs. $4.14 \mathrm{mg} / \mathrm{g}$ in the sham control group), a $23.1 \%$ increase in cardiomyocyte cross sectional area (2.05 vs. 1.66 microns $^{2}$ in the control group), and $\sim 12 \%$ increase in the anterior and posterior wall thicknesses in diastole (1.13 vs. $1.0 \mathrm{~mm}$ in the sham control group; Figure 3A-3F, Table 1). In contrast, CHIP -/- mice in the run group exhibited an exaggerated hypertrophy compared to their baseline, resulting in a $49.5 \%$ greater HW/BW than hearts from CHIP -/- sham (7.98 vs. $5.35 \mathrm{mg} / \mathrm{g}$ in the sham control group), a 69.9\% increase in cardiomyocyte cross sectional areas ( 2.95 vs. 1.74 microns $\left.^{2}\right)$, and $\sim 40-46 \%$ greater thicknesses of the anterior $(\sim 46.3 \%$, 1.47 vs. $1.0 \mathrm{~mm}$ ) and posterior ( $40 \%, 1.35$ vs. $0.97 \mathrm{~mm})$ ventricular wall thicknesses in diastole as determined by echocardiography (Table 1). CHIP -/- mice have previously been shown to have a progressive weight loss over time due to decreases in muscle and fat mass (atrophy) ${ }^{29}$. This may account for the disproportionate increase in HW/BW vs. the crosssectional areas of the CHIP -/- and type mice, which has previously been reported ${ }^{29}$. The running performance of both CHIP -/- and wild-type mice improved during the course of voluntary running (Supplemental Figure 1A). No differences in the soleus skeletal muscle weights were identified in CHIP - /- mice after running, indicating the increases in cardiac hypertrophy in the CHIP -/- mice were not a uniform response of CHIP -/- striated muscle (Supplemental Figure 2).

The exaggerated changes observed in hearts of CHIP -/- in response to running suggested CHIP's involvement in the regulation of cardiac hypertrophy. Activation of the IGF-1 signaling pathway enhances the development of muscle hypertrophy in response to exercise ${ }^{48,49}$. IGF-1 activates PI-3-kinase, which phosphorylates pyruvate dehydrogenase kinase (PDK), which then phosphorylates Akt, activating its ability to phosphorylate downstream GSK3 $\beta$ and p70 S6 kinase ${ }^{50}$. Voluntary running in mice induces the IGF-1/ PI3K/Akt signal transduction pathway, ultimately resulting in increased GSK3 $\beta$ signaling and leading to physiologic cardiac hypertrophy 31,51 . Recent studies have implicated CHIP in the regulation of Akt in neurons. Specifically, during stress, CHIP ubiquitinates and degrades Akt in an HSP90 complex-dependent manner 5, 6,52. Conversely, Akt activity tightly regulates CHIP expression, suggesting a feedback response mechanism $5,6,52$. Since CHIP negatively regulates Akt signaling critical to the development of physiologic cardiac hypertrophy, challenging CHIP $-/-$ mice to voluntary running would be expected to have an enhanced Akt response and an enhanced cardiac hypertrophy, which is consistent with our phenotypic findings above.

To investigate whether CHIP plays a role in regulating Akt signaling in cardiomyocytes as it does in neurons under stress, we performed Western immunoblot analysis on HL-1 cardiacderived cells stimulated with IGF-1 ${ }^{53-55}$. When stimulated with IGF-1, HL-1 cell lines with stable shRNA CHIP knockdown exhibited an exaggerated p-Akt (ser473) compared to shRNA scramble controls (Figure 4A/4B). Since recent studies have linked the Akt signaling pathway to the regulation of autophagy 56,57 , we next determined how CHIP's regulation of Akt might be linked to the autophagic flux identified in the shRNA CHIP (-/-) cells. Interestingly, we identified that knocking down CHIP expression resulted in an enhanced LC3B II expression compared to controls in the presence of bafilomycin both at baseline and in the presence of IGF-1 (Figure 4C). Taken together, these findings suggested that cardiomyocytes lacking CHIP experienced an enhanced Akt signaling that was associated with an increase in autophagic flux. 
The enhanced hypertrophy and performance seen in CHIP-/- mice is not associated with enhanced fibrosis or decreased cardiac function

Histological analysis of hearts from control and running CHIP -/- mice was performed to determine any morphological and fibrotic changes, indicative of pathological hypertrophy. Tissue sections taken from hearts of CHIP - /- mice in the running group exhibited no cellular infiltrates or fibrosis, as determined by staining sections with either Mason's Trichrome or H\&E, respectively (Figure 5A, Supplemental Figure 3). A similar finding was seen in tissue sections taken from wild-type mice in the running group (Figure 5A, Supplemental Figure 3). RT-PCR analysis of $\beta$-myosin heavy chain ( $\beta$-MHC), brain natriuretic peptide (BNP), and atrial natriuretic factor (ANF) mRNA expression (genes associated with the "fetal program" seen in pathological cardiac hypertrophy) revealed no significant increases in gene expression in the hearts of CHIP -/- compared to wild-type mice in either the control or running groups, although a near two-fold change in ANF was seen in CHIP -/- hearts at baseline and after running (Figure 5B). Previous studies have reported the CHIP -/- heart function is stable for up to a year of age ${ }^{7}$; however, CHIP -/mice demonstrate an increased cellular senescence. So it is not clear if this increased ANF expression reflects early "fetal gene" expression or is related to other non-related issues. Despite the fact that CHIP -/- mice exhibited an exaggerated cardiac hypertrophy compared to wild-type mice after running, no change in cardiac systolic function between the two groups was observed, as indicated by echocardiographic determination of fractional shortening \% and ejection fraction \% (Figure 5C). Differences in cardiac ATP levels were not seen in CHIP -/- mice compared to controls either (Supplemental Figure 2). These results indicate that the increased cardiac hypertrophy seen in CHIP -/- mice following 5 weeks of voluntary running is not associated with fibrosis, histological evidence of pathology, or defects in cardiac function at the time point investigated.

\section{Discussion}

In this report, we have used a mouse model of unloaded, voluntary running to identify for the first time that the ubiquitin ligase/co-chaperone CHIP (carboxyl terminus of Hsp70interacting protein) regulates physiologic cardiac hypertrophy and autophagy. This is an exciting finding given the previous reports identifying cardiac CHIP as a key regulator of cell death in the context of ischemia and hyperglycemia-induced cardiomyocyte injury $7,58,59$.

In the present study we identified that CHIP -/- hearts had enhanced autophagy determined by TEM, real time analysis of proteins involved in autophagy, including Atg7, Atg5, and Vps34. Our understanding of the role autophagy plays in the heart has increased tremendously in the past couple of years. There are numerous molecular components involved with autophagy, including Atg1 and Atg4-12 ${ }^{60}$. In addition, numerous signaling pathways regulate autophagy, including Akt regulated mTOR, AMPK and the p53 signaling cascade ${ }^{60}$. Autophagy of damaged cellular components, including the degradation of damaged cellular components as a means of protein and organelle protein quality control, occurs under physiological conditions in the heart, as illustrated in mice lacking either Atg5 or Atg7 (inhibiting autophagy), which suffer from cardiac failure without any inducing stimuli 61,62 . However, autophagy is also critical for afterload-induced changes in the heart, as well as during myocardial infarction and ischemia/reperfusion insults ${ }^{60}$.

Despite what is known about the role of autophagy in basal cardiac regulation and response to cardiac disease states, a role for autophagy in physiologic cardiac hypertrophy, has not been previously published, to our knowledge. However, in skeletal muscle, strenuous exercise inducing muscle damage has been reported to induce an autophagic response ${ }^{63}$. Specifically, in mice challenged with 9 hours of running, necrotic fibers first appear within 
24 hours after exertion. An enhanced autophagic response in these mice is most prominent between 2 and 7 days after exertion, illustrated by vacuoles with double or single limiting membranes containing mitochondria at various stages of degradation ${ }^{63}$. The enhanced autophagy in response to running is thought to be related to the breakdown of cellular constituents that could be recycled to provide resources for regenerating muscle fibers ${ }^{63}$. In addition to exercise, both muscle damage and the accumulation of misfolded proteins are known to induce autophagy in cardiomyocytes ${ }^{64,65}$. In mouse models of human cardiomyopathies, genetic mutations of the small heat shock protein aB-Crystallin $\left(\mathrm{CryAB} \mathrm{B}^{\mathrm{R} 120 \mathrm{G}}\right)$ result in the accumulation of misfolded $\mathrm{CryAB}^{\mathrm{R} 120 \mathrm{G}}$ protein in the form of preamyloid oligomers and aggresomes ${ }^{64}$. These oligomers and aggresome then induce a severe cardiomyopathy resulting from an inhibition of autophagy ${ }^{64}$. Further inhibiting autophagy by silencing Atg7, a required intermediate for autophagy, results in an increase in CryAB ${ }^{\mathrm{R} 120 \mathrm{G}}$ aggregate content and cytotoxicity. Conversely, enhanced Atg7 expression rescues the $\mathrm{Cry}_{\mathrm{AB}} \mathrm{R}^{\mathrm{R} 120 \mathrm{G}}$ autophagic deficiency and attenuates misfolded protein accumulation and aggregates in cardiomyocytes, illustrating the critical role of autophagy in clearing misfolded $\mathrm{CryAB}^{\mathrm{R} 120 \mathrm{G}}$ proteins ${ }^{64}$. Extending these elegant studies of CryAB ${ }^{\mathrm{R} 120 \mathrm{G}}$, subsequent studies have demonstrated that expressing an 83 residue, misfolded polyglutamine (PQ83) peptide in the heart itself can induce heat failure, whereas a non-amyloid-forming polyglutamine peptide of 19 residues (PQ19) does not ${ }^{66}$. Taken together, these studies illustrate the role for an autophagic response in exercise and demonstrate an advantage to enhancing autophagy to clear misfolded proteins, resulting in preserved cardiomyocyte viability and function. Similarly, the enhanced performance seen in the CHIP -/- mice in the current study may be due to enhanced autophagy after running that more efficiently clears misfolded proteins and/or mitochondria that accumulate during voluntary running.

We have previously demonstrated that the CHIP -/- mouse used in the current study has altered protein quality control, leading to an increase in misfolded proteins ${ }^{29}$. The increase in autophagy in the hearts from CHIP -/- mice reported in this study may reflect a compensatory mechanism used by cardiomyocytes to decrease the burden of damaged or misfolded proteins that arise as a result of the increase in cardiac work load. Alternatively, the increased autophagic activity may indicate that, under normal physiological conditions, CHIP inhibits autophagy. Since Hsc70 is critical for both CHIP's chaperone functions and the process of chaperone mediated autophagy, it is possible that when CHIP is present it targets $\mathrm{Hsc70}$ for ubiquitination and proteasomal degradation thereby limiting its availability for autophagic activity. Regardless of the mechanism, these findings suggest a role for cardiac CHIP in autophagy in general, and in chaperone-mediated autophagy more specifically, during exercise-mediated cardiac stress.

Recent studies have implicated CHIP in the regulation of Akt signaling in neuronal cells, consistent with the findings in the current paper $5,6,52$. Akt is required for the development of the physiologic cardiac hypertrophy that occurs in response to exercise and IGF-1 stimulation 67,68 . At the same time, signaling through the Akt pathway antagonizes the development of pathologic hypertrophy $67,69,70$. IGF-1, increased through different forms of exercise, mediates the physiologic growth of cardiomyocytes by stimulating an increase in GSK $3 \beta$ phosphorylation, thereby inhibiting its activity and inducing increases in protein synthesis via mTOR ${ }^{71}$. Our observations of enhanced Akt/GSK3 $\beta$ signaling in CHIP-/cardiomyocytes following voluntary exercise explains, in part, the enhanced physiologic hypertrophy identified in these mice. It also indicates a role for CHIP in regulating Akt signaling in exercise-induced cardiac hypertrophy.

Previous studies have begun to form a link between CHIP and the regulation of Akt in neurons, but the exact nature of this relationship in the context of the current study is not 
clear $5,6,52$. Similar to the accumulation of proteotoxic aggregates that form in human heart failure 72 and in genetic cardiac diseases described above ${ }^{73-75}$, Alzheimer's disease results in the accumulation of the microtubule-associated protein tau that forms fibrillar aggregates and become toxic to the neurons in which they form ${ }^{52}$. During stress, Akt is ubiquitinated and degraded by CHIP; Akt also prevents CHIP-induced tau ubiquitination and degradation ${ }^{52}$. This feedback mechanism(s) between kinase and ubiquitin ligase illustrates the novel interaction between tau kinases (Akt) and protein quality control (CHIP) that lead to the common pathways of proteotoxity and dysfunction seen in Alzheimer's disease ${ }^{52}$. In the CHIP - /- mice challenged with running described in the current manuscript, the link between Akt-induced cardiomyocyte growth and protein quality control may be similarly linked. CHIP may attenuate both Akt signaling and autophagy in the heart during exercise, resulting in both the beneficial growth (Akt activation) and enhanced autophagy (protein quality control including clearance of misfolded proteins). The details of how CHIP regulates Akt remains to be delineated in the heart, but possibly involves the proteasomal degradation of Akt during stress, autophagy and other signaling pathways involved in physiologic and pathologic hypertrophy.

Recent studies have linked the regulation of Akt signaling to autophagy. Stimulation of IGF-1 activates downstream PI3K, Akt, and the transcription factors FOXO3 \& FOXO4. Cell lines ectopically expressing conditionally active variants of PI3K, Akt, FOXO3, and FOXO4 have recently been identified to up-regulate the expression of glutamine synthetase $^{56}$. The activation of FOXO-induced glutamine synthetase expression increases the level of autophagy; the mechanism is believed to involve the glutamine synthetase regulation of mTOR, which is evolutionarily conserved to negatively regulate autophagy. The enhanced FOXO3 activation in these studies resulted in an increased level of autophagy measured by LC3 lipidation, p62 degradation, and the identification of autophagosomal markers ${ }^{56}$. While the present studies have not definitively proven that the enhanced Akt signaling seen in response to running and IGF-1 is the cause of enhanced autophagy through its activation of FOXO, it is one possible mechanism that would explain the unexpected findings in the CHIP -/- hearts reported here.

While CHIP -/- hearts challenged with voluntary running exhibited increased autophagy by molecular markers in the current study, transmission electron microscopy revealed clear indications that the autophagy occurred predominantly in the areas where mitochondria were found, with primarily mitochondria substrates identified within these enveloped vacuoles (Figure 1). Mitochondrial autophagy (mitophagy) was first described the heart in 1980 following hypoxia in perfused rabbit hearts-it's presence was attributed to repair mechanisms in damaged cells ${ }^{76}$. Since this time, mitophagy has been shown to have a role in mitochondrial protein quality control ${ }^{77-81}$ and disease ${ }^{82}$. The role of mitophagy in protein quality control appears to play a critical role in maintaining mitochondrial integrity critical to cellular homeostasis. When energy demand is low, having too many mitochondria can be detrimental by generating more reactive oxygen species and if uncoupled, can consume excess ATP ${ }^{83}$. Eliminating mitochondria, particularly those that are damaged or unstable and prone to inducing apoptosis, can reduce the damage to both neighboring mitochondria and the entire cell ${ }^{84}$. Autophagic removal of mitochondria follows both induction and inhibition of apoptosis 85,86 suggesting a role for cell survival following mitochondrial injury. The process of mitochondrial biogenesis, whereby growth and division of preexisting mitochondria occurs, requires the coordination of multiple processes, including synthesis of the inner and outer mitochondrial membranes, mitochondrial proteins; synthesis and import of proteins encoded by the nuclear genome; replication of mitochondrial DNA, and mitochondrial fission and fusion ${ }^{12,87}$. This subsequent critical mitochondrial turnover then involves mitophagy followed by biogenesis ${ }^{87}$. 
Basal levels of autophagy are required for cardiomyocytes to function and survive. Autophagic recycling of damaged cellular proteins and organelles allows them to be efficiently reused. When autophagic pathways are disrupted in the adult heart by inactivating Atg5 or Atg7 genes, cardiac hypertrophy rapidly develops, along with left ventricular dilation and diminished cardiac output ${ }^{88,89}$. Danon disease, also known as glycogen storage disease type IIB, is marked by severe and progressive myopathy resulting from defective autophagy, specifically a defect in the fusion of lysosomes with autophagosomes 90,91 . Suppression of autophagy during fasting reduces intracellular ATP and results in diminished cardiac function ${ }^{92}$. Multiple recent studies illustrate that inducing autophagy can either inhibit the progression of cardiac disease or contribute to the pathophysiology to accelerate disease progression ${ }^{93-95}$. Enhancing autophagy is protective during ischemia ${ }^{96}$; and conversely activating autophagy in pressure overload-induced cardiac hypertrophy ${ }^{97}$ or after ischemia reperfusion injury 96 is maladaptive. Autophagic flux is enhanced by the amount of pressure overload in vivo ${ }^{97,98}$. Increasing autophagy by overexpression of cardiomyocyte Beclin 1, pressure overload induced cardiac hypertrophy results in a rapid transition to heart failure ${ }^{99}$, whereas decreasing autophagy in Beclin 1 haplosufficient mice attenuated the remodeling in pressure overload induced remodeling ${ }^{97}$. In the context of proteotoxic cardiomyopathy due to mutations in cardiac $\mathrm{aB}$-crystallin $\left(\mathrm{CryAB}^{\mathrm{R} 120 \mathrm{G}}\right)$, resulting in an increase is misfolded $\mathrm{CryAB}^{\mathrm{R} 120 \mathrm{G}}$ protein, enhanced autophagy helps remove the accumulating toxic, misfolded, oxidized mutant proteins ${ }^{20}$, giving support to the concept that regulation of autophagy can be therapeutic, depending on the context of the underlying cause of disease ${ }^{60}$. Recent studies have also suggested an interplay between autophagy, glucose metabolism and cardiac hypertrophy; autophagy may also play a role in supplying amino acids, nucleotides, sugars, and lipids to the energy pathways critical in the heart (see recent reviews 95,100 ).

While the enhanced Akt signaling seen in response to the challenge of physiological hypertrophy induced by voluntary running appears beneficial in the current study, CHIP -/mice are more susceptible to injurious challenges. For example, in response to ischemia reperfusion injury, CHIP - /- mice exhibit decreased survival and increased incidence of arrhythmias during reperfusion ${ }^{7}$. In addition, the size of the infarct area in the hearts of CHIP $-/-$ mice is $>50 \%$ larger than sibling wild-type controls, an observation that correlates with an increase in apoptosis of endothelial cells in intramural vessels ${ }^{7}$. This increase in endothelial cell apoptosis in the hearts of CHIP $-/-$ mice is due in part to CHIP's role as an endogenous p53 antagonist, suppressing p53 activity by ubiquitinating it and targeting it for degradation by the proteasome ${ }^{58}$. In experimental myocardial infarction induced in vivo, CHIP overexpression prevents $\mathrm{p} 53$ accumulation, which in turn, prevents apoptosis, indicating one of the mechanisms by which CHIP is cardioprotective ${ }^{58}$. In hyperglycemiainduced cardiomyocyte damage, CHIP regulates the steady state protein levels of the transcription factor GATA4, likely by ubiquitin-dependent degradation ${ }^{59}$. These studies demonstrate CHIP's cardioprotective function of regulating key proteins involved in the development of cardiac ischemia and pathologic cardiac hypertrophy, including the transcription factors p53 and GATA4, respectfully. However, in other contexts, CHIP may actually attenuate the beneficial signaling processes mediated by another key signaling pathway, the Akt/GSK3 $\beta$ pathway, which is pivotal in the heart's response to physiologic stress and exercise.

\section{Supplementary Material}

Refer to Web version on PubMed Central for supplementary material. 


\section{Acknowledgments}

The authors wish to thank Mark Ranek, $\mathrm{PhD}$ for his guidance in measuring autophagic flux in vivo, Vicky Madden and Steven Ray in the Microscopy Services Laboratory in the UNC Department of Pathology \& Laboratory Medicine for their assistance with the electron microscopy experiments, and Janice Weaver in the UNC Animal Histopathology Laboratory for assistance in preparing histological specimens. We also wish to thank Dr. Andrea Portbury for her valuable critical discussion during preparation of this manuscript.

Disclosures: This work is supported by the National Institutes of Health (R01GM061728 to C.P., R01HL104129 to M.W.) and the Leducq Foundation (to C.P. and M.W.).

\section{References}

1. Jiang J, Ballinger CA, Wu Y, Dai Q, Cyr DM, Hohfeld J, Patterson C. CHIP is a U-box-dependent E3 ubiquitin ligase: identification of $\mathrm{Hsc} 70$ as a target for ubiquitylation. J Biol Chem. 2001; 276:42938-42944. [PubMed: 11557750]

2. Cyr DM, Hohfeld J, Patterson C. Protein quality control: U-box-containing E3 ubiquitin ligases join the fold. Trends Biochem Sci. 2002; 27:368-375. [PubMed: 12114026]

3. Connell P, Ballinger CA, Jiang J, Wu Y, Thompson LJ, Hohfeld J, Patterson C. The co-chaperone CHIP regulates protein triage decisions mediated by heat-shock proteins. Nat Cell Biol. 2001; 3:9396. [PubMed: 11146632]

4. Petrucelli L, Dickson D, Kehoe K, Taylor J, Snyder H, Grover A, De Lucia M, McGowan E, Lewis J, Prihar G, Kim J, Dillmann WH, Browne SE, Hall A, Voellmy R, Tsuboi Y, Dawson TM, Wolozin B, Hardy J, Hutton M. CHIP and Hsp70 regulate tau ubiquitination, degradation and aggregation. Hum Mol Genet. 2004; 13:703-714. [PubMed: 14962978]

5. Dickey CA, Kamal A, Lundgren K, Klosak N, Bailey RM, Dunmore J, Ash P, Shoraka S, Zlatkovic J, Eckman CB, Patterson C, Dickson DW, Nahman NS Jr, Hutton M, Burrows F, Petrucelli L. The high-affinity HSP90-CHIP complex recognizes and selectively degrades phosphorylated tau client proteins. J Clin Invest. 2007; 117:648-658. [PubMed: 17304350]

6. Dickey CA, Patterson C, Dickson D, Petrucelli L. Brain CHIP: removing the culprits in neurodegenerative disease. Trends Mol Med. 2007; 13:32-38. [PubMed: 17127096]

7. Zhang C, Xu Z, He XR, Michael LH, Patterson C. CHIP, a cochaperone/ubiquitin ligase that regulates protein quality control, is required for maximal cardioprotection after myocardial infarction in mice. Am J Physiol Heart Circ Physiol. 2005; 288:H2836-2842. [PubMed: 15665051]

8. Arndt V, Dick N, Tawo R, Dreiseidler M, Wenzel D, Hesse M, Furst DO, Saftig P, Saint R, Fleischmann BK, Hoch M, Hohfeld J. Chaperone-assisted selective autophagy is essential for muscle maintenance. Curr Biol. 2010; 20:143-148. [PubMed: 20060297]

9. Massey AC, Zhang C, Cuervo AM. Chaperone-mediated autophagy in aging and disease. Curr Top Dev Biol. 2006; 73:205-235. [PubMed: 16782460]

10. Golbidi S, Laher I. Molecular mechanisms in exercise-induced cardioprotection. Cardiol Res Pract. 2011; 2011:972807. [PubMed: 21403846]

11. Chen CY, Hsu HC, Lee BC, Lin HJ, Chen YH, Huang HC, Ho YL, Chen MF. Exercise training improves cardiac function in infarcted rabbits: involvement of autophagic function and fatty acid utilization. Eur J Heart Fail. 2010; 12:323-330. [PubMed: 20335351]

12. Gottlieb RA, Mentzer RM. Autophagy during cardiac stress: joys and frustrations of autophagy. Annu Rev Physiol. 2010; 72:45-59. [PubMed: 20148666]

13. Cao DJ, Gillette TG, Hill JA. Cardiomyocyte autophagy: remodeling, repairing, and reconstructing the heart. Curr Hypertens Rep. 2009; 11:406-411. [PubMed: 19895751]

14. Ma X, Liu H, Foyil SR, Godar RJ, Weinheimer CJ, Diwan A. Autophagy is impaired in cardiac ischemia-reperfusion injury. Autophagy. 2012; 8:1394-1396. [PubMed: 22889942]

15. Ma X, Liu H, Foyil SR, Godar RJ, Weinheimer CJ, Hill JA, Diwan A. Impaired autophagosome clearance contributes to cardiomyocyte death in ischemia/reperfusion injury. Circulation. 2012; 125:3170-3181. [PubMed: 22592897] 
16. Huang C, Yitzhaki S, Perry CN, Liu W, Giricz Z, Mentzer RM Jr, Gottlieb RA. Autophagy induced by ischemic preconditioning is essential for cardioprotection. J Cardiovasc Transl Res. 2010; 3:365-373. [PubMed: 20559777]

17. Hausenloy DJ, Ong SB, Yellon DM. The mitochondrial permeability transition pore as a target for preconditioning and postconditioning. Basic Res Cardiol. 2009; 104:189-202. [PubMed: 19242644]

18. Hamacher-Brady A, Brady NR, Gottlieb RA. Enhancing macroautophagy protects against ischemia/reperfusion injury in cardiac myocytes. J Biol Chem. 2006; 281:29776-29787. [PubMed: 16882669]

19. Huang C, Andres AM, Ratliff EP, Hernandez G, Lee P, Gottlieb RA. Preconditioning involves selective mitophagy mediated by Parkin and p62/SQSTM1. PLoS One. 2011; 6:e20975. [PubMed: 21687634]

20. Tannous P, Zhu H, Johnstone JL, Shelton JM, Rajasekaran NS, Benjamin IJ, Nguyen L, Gerard RD, Levine B, Rothermel BA, Hill JA. Autophagy is an adaptive response in desmin-related cardiomyopathy. Proc Natl Acad Sci U S A. 2008; 105:9745-9750. [PubMed: 18621691]

21. Glembotski CC. Endoplasmic reticulum stress in the heart. Circ Res. 2007; 101:975-984. [PubMed: 17991891]

22. Cox LS, Mattison JA. Increasing longevity through caloric restriction or rapamycin feeding in mammals: common mechanisms for common outcomes? Aging Cell. 2009; 8:607-613. [PubMed: 19678809]

23. Lerman I, Harrison BC, Freeman K, Hewett TE, Allen DL, Robbins J, Leinwand LA. Genetic variability in forced and voluntary endurance exercise performance in seven inbred mouse strains. J Appl Physiol. 2002; 92:2245-2255. [PubMed: 12015333]

24. Allen DL, Harrison BC, Maass A, Bell ML, Byrnes WC, Leinwand LA. Cardiac and skeletal muscle adaptations to voluntary wheel running in the mouse. J Appl Physiol. 2001; 90:1900-1908. [PubMed: 11299284]

25. Massett MP, Berk BC. Strain-dependent differences in responses to exercise training in inbred and hybrid mice. Am J Physiol Regul Integr Comp Physiol. 2005; 288:R1006-1013. [PubMed: 15618348]

26. Miyazaki M, Esser KA. Cellular mechanisms regulating protein synthesis and skeletal muscle hypertrophy in animals. J Appl Physiol. 2009; 106:1367-1373. [PubMed: 19036895]

27. Mackenzie MG, Hamilton DL, Murray JT, Baar K. mVps34 is activated by an acute bout of resistance exercise. Biochem Soc Trans. 2007; 35:1314-1316. [PubMed: 17956340]

28. Ilback NG, Friman G, Squibb RL, Johnson AJ, Balentine DA, Beisel WR. The effect of exercise and fasting on the myocardial protein and lipid metabolism in experimental bacterial myocarditis. Acta Pathol Microbiol Immunol Scand A. 1984; 92:195-204. [PubMed: 6208744]

29. Min JN, Whaley RA, Sharpless NE, Lockyer P, Portbury AL, Patterson C. CHIP deficiency decreases longevity, with accelerated aging phenotypes accompanied by altered protein quality control. Mol Cell Biol. 2008; 28:4018-4025. [PubMed: 18411298]

30. Willis MS, Ike C, Li L, Wang DZ, Glass DJ, Patterson C. Muscle ring finger 1, but not muscle ring finger 2, regulates cardiac hypertrophy in vivo. Circ Res. 2007; 100:456-459. [PubMed: 17272810]

31. Konhilas JP, Widegren U, Allen DL, Paul AC, Cleary A, Leinwand LA. Loaded wheel running and muscle adaptation in the mouse. Am J Physiol Heart Circ Physiol. 2005; 289:H455-465. [PubMed: 15734890]

32. Li HH, Willis MS, Lockyer P, Miller N, McDonough H, Glass DJ, Patterson C. Atrogin-1 inhibits Akt-dependent cardiac hypertrophy in mice via ubiquitin-dependent coactivation of Forkhead proteins. J Clin Invest. 2007; 117:3211-3223. [PubMed: 17965779]

33. Wysong A, Couch M, Shadfar S, Li L, Rodriguez JE, Asher S, Yin X, Gore M, Baldwin A, Patterson C, Willis MS. NF-kappaB Inhibition Protects against Tumor-Induced Cardiac Atrophy in Vivo. Am J Pathol. 2011; 178:1059-1068. [PubMed: 21356358]

34. Willis MS, Schisler JC, Li L, Rodriguez JE, Hilliard EG, Charles PC, Patterson C. Cardiac muscle ring finger-1 increases susceptibility to heart failure in vivo. Circ Res. 2009; 105:80-88. [PubMed: 19498199] 
35. Claycomb WC, Lanson NA Jr, Stallworth BS, Egeland DB, Delcarpio JB, Bahinski A, Izzo NJ Jr. HL-1 cells: a cardiac muscle cell line that contracts and retains phenotypic characteristics of the adult cardiomyocyte. Proc Natl Acad Sci U S A. 1998; 95:2979-2984. [PubMed: 9501201]

36. Su H, Li F, Ranek MJ, Wei N, Wang X. COP9 signalosome regulates autophagosome maturation. Circulation. 2011; 124:2117-2128. [PubMed: 21986281]

37. Su H, Wang X. Autophagy and p62 in cardiac protein quality control. Autophagy. 2011; 7:13821383. [PubMed: 21997373]

38. Ballinger CA, Connell P, Wu Y, Hu Z, Thompson LJ, Yin LY, Patterson C. Identification of CHIP, a novel tetratricopeptide repeat-containing protein that interacts with heat shock proteins and negatively regulates chaperone functions. Mol Cell Biol. 1999; 19:4535-4545. [PubMed: 10330192]

39. Dai Q, Qian SB, Li HH, McDonough H, Borchers C, Huang D, Takayama S, Younger JM, Ren HY, Cyr DM, Patterson C. Regulation of the cytoplasmic quality control protein degradation pathway by BAG2. J Biol Chem. 2005; 280:38673-38681. [PubMed: 16169850]

40. Crippa V, Sau D, Rusmini P, Boncoraglio A, Onesto E, Bolzoni E, Galbiati M, Fontana E, Marino M, Carra S, Bendotti C, De Biasi S, Poletti A. The small heat shock protein B8 (HspB8) promotes autophagic removal of misfolded proteins involved in amyotrophic lateral sclerosis (ALS). Hum Mol Genet. 2010; 19:3440-3456. [PubMed: 20570967]

41. Gurusamy N, Das DK. Is autophagy a double-edged sword for the heart? Acta Physiol Hung. 2009; 96:267-276. [PubMed: 19706370]

42. Chiang HL, Dice JF. Peptide sequences that target proteins for enhanced degradation during serum withdrawal. J Biol Chem. 1988; 263:6797-6805. [PubMed: 3360807]

43. Cuervo AM, Gomes AV, Barnes JA, Dice JF. Selective degradation of annexins by chaperonemediated autophagy. J Biol Chem. 2000; 275:33329-33335. [PubMed: 10938088]

44. Dice JF. Peptide sequences that target cytosolic proteins for lysosomal proteolysis. Trends Biochem Sci. 1990; 15:305-309. [PubMed: 2204156]

45. Roszek K, Gniot-Szulzycka J. Lysosomal membrane glycoprotein lamp2a--receptor for chaperonemediated degradation of cytosolic proteins. Postepy Biochem. 2005; 51:88-94. [PubMed: 16209346]

46. Cuervo AM, Dice JF. Regulation of lamp2a levels in the lysosomal membrane. Traffic. 2000; 1:570-583. [PubMed: 11208145]

47. Cuervo AM, Dice JF. Unique properties of lamp2a compared to other lamp2 isoforms. J Cell Sci. 2000; 113 Pt 24:4441-4450. [PubMed: 11082038]

48. McMullen JR, Izumo S. Role of the insulin-like growth factor 1 (IGF1)/phosphoinositide-3-kinase (PI3K) pathway mediating physiological cardiac hypertrophy. Novartis Found Symp. 2006; 274:90-111. discussion 111-117, 152-115, 272-116. [PubMed: 17019808]

49. McMullen JR, Shioi T, Huang WY, Zhang L, Tarnavski O, Bisping E, Schinke M, Kong S, Sherwood MC, Brown J, Riggi L, Kang PM, Izumo S. The insulin-like growth factor 1 receptor induces physiological heart growth via the phosphoinositide 3-kinase(p110alpha) pathway. J Biol Chem. 2004; 279:4782-4793. [PubMed: 14597618]

50. Dorn GW 2nd, Force T. Protein kinase cascades in the regulation of cardiac hypertrophy. J Clin Invest. 2005; 115:527-537. [PubMed: 15765134]

51. Gosselin H, Beliveau L, Burelle Y, Clement R, Lajoie C, El-Helou V, Calderone A. Disparate regulation of signaling proteins after exercise and myocardial infarction. Med Sci Sports Exerc. 2006; 38:455-462. [PubMed: 16540832]

52. Dickey CA, Koren J, Zhang YJ, Xu YF, Jinwal UK, Birnbaum MJ, Monks B, Sun M, Cheng JQ, Patterson C, Bailey RM, Dunmore J, Soresh S, Leon C, Morgan D, Petrucelli L. Akt and CHIP coregulate tau degradation through coordinated interactions. Proc Natl Acad Sci U S A. 2008; 105:3622-3627. [PubMed: 18292230]

53. Guo W, Kamiya K, Yasui K, Kodama I, Toyama J. alpha1-adrenoceptor agonists and IGF-1, myocardial hypertrophic factors, regulate the Kv1.5 K+ channel expression differentially in cultured newborn rat ventricular cells. Pflugers Arch. 1998; 436:26-32. [PubMed: 9560443]

54. Long CS, Kariya K, Karns L, Simpson PC. Trophic factors for cardiac myocytes. J Hypertens Suppl. 1990; 8:S219-224. [PubMed: 1965655] 
55. Liu J, Liu Z, Huang F, Xing Z, Wang H, Li Z. Pioglitazone inhibits hypertrophy induced by high glucose and insulin in cultured neonatal rat cardiomyocytes. Pharmazie. 2007; 62:925-929. [PubMed: 18214344]

56. van der Vos KE, Eliasson P, Proikas-Cezanne T, Vervoort SJ, van Boxtel R, Putker M, van Zutphen IJ, Mauthe M, Zellmer S, Pals C, Verhagen LP, Groot Koerkamp MJ, Braat AK, Dansen TB, Holstege FC, Gebhardt R, Burgering BM, Coffer PJ. Modulation of glutamine metabolism by the PI(3)K-PKB-FOXO network regulates autophagy. Nat Cell Biol. 2012; 14:829-837. [PubMed: 22820375]

57. Sandri M. FOXOphagy path to inducing stress resistance and cell survival. Nat Cell Biol. 2012; 14:786-788. [PubMed: 22854812]

58. Naito AT, Okada S, Minamino T, Iwanaga K, Liu ML, Sumida T, Nomura S, Sahara N, Mizoroki T, Takashima A, Akazawa H, Nagai T, Shiojima I, Komuro I. Promotion of CHIP-mediated p53 degradation protects the heart from ischemic injury. Circ Res. 2010; 106:1692-1702. [PubMed: 20413784]

59. Kobayashi S, Mao K, Zheng H, Wang X, Patterson C, O'Connell TD, Liang Q. Diminished GATA4 protein levels contribute to hyperglycemia-induced cardiomyocyte injury. J Biol Chem. 2007; 282:21945-21952. [PubMed: 17525155]

60. Nemchenko A, Chiong M, Turer A, Lavandero S, Hill JA. Autophagy as a therapeutic target in cardiovascular disease. J Mol Cell Cardiol. 2011

61. Nakai A, Yamaguchi O, Takeda T, Higuchi Y, Hikoso S, Taniike M, Omiya S, Mizote I, Matsumura Y, Asahi M, Nishida K, Hori M, Mizushima N, Otsu K. The role of autophagy in cardiomyocytes in the basal state and in response to hemodynamic stress. Nat Med. 2007; 13:619624. [PubMed: 17450150]

62. Taneike M, Yamaguchi O, Nakai A, Hikoso S, Takeda T, Mizote I, Oka T, Tamai T, Oyabu J, Murakawa T, Nishida K, Shimizu T, Hori M, Komuro I, Shirasawa T, Mizushima N, Otsu K. Inhibition of autophagy in the heart induces age-related cardiomyopathy. Autophagy. 2010; 6 Epub ahead of print.

63. Salminen A, Vihko V. Autophagic response to strenuous exercise in mouse skeletal muscle fibers. Virchows Arch B Cell Pathol Incl Mol Pathol. 1984; 45:97-106. [PubMed: 6142562]

64. Pattison JS, Osinska H, Robbins J. Atg7 Induces Basal Autophagy and Rescues Autophagic Deficiency in CryABR120G Cardiomyocytes. Circ Res. 2011; 109:151-160. [PubMed: 21617129]

65. Pattison JS, Robbins J. Autophagy and proteotoxicity in cardiomyocytes. Autophagy. 2011; 7:1259-1260. [PubMed: 21677510]

66. Pattison JS, Sanbe A, Maloyan A, Osinska H, Klevitsky R, Robbins J. Cardiomyocyte expression of a polyglutamine preamyloid oligomer causes heart failure. Circulation. 2008; 117:2743-2751. [PubMed: 18490523]

67. DeBosch B, Treskov I, Lupu TS, Weinheimer C, Kovacs A, Courtois M, Muslin AJ. Akt1 is required for physiological cardiac growth. Circulation. 2006; 113:2097-2104. [PubMed: 16636172]

68. Ibebunjo C, Eash JK, Li C, Ma Q, Glass DJ. Voluntary running, skeletal muscle gene expression, and signaling inversely regulated by orchidectomy and testosterone replacement. Am J Physiol Endocrinol Metab. 2011; 300:E327-340. [PubMed: 21045173]

69. DeBosch B, Sambandam N, Weinheimer C, Courtois M, Muslin AJ. Akt2 regulates cardiac metabolism and cardiomyocyte survival. J Biol Chem. 2006; 281:32841-32851. [PubMed: 16950770]

70. Muslin AJ, DeBosch B. Role of Akt in cardiac growth and metabolism. Novartis Found Symp. 2006; 274:118-126. discussion 126-131, 152-115, 272-116. [PubMed: 17019809]

71. Kemi OJ, Ceci M, Wisloff U, Grimaldi S, Gallo P, Smith GL, Condorelli G, Ellingsen O. Activation or inactivation of cardiac Akt/mTOR signaling diverges physiological from pathological hypertrophy. J Cell Physiol. 2008; 214:316-321. [PubMed: 17941081]

72. Sanbe A, Osinska H, Saffitz JE, Glabe CG, Kayed R, Maloyan A, Robbins J. Desmin-related cardiomyopathy in transgenic mice: a cardiac amyloidosis. Proc Natl Acad Sci U S A. 2004; 101:10132-10136. [PubMed: 15220483] 
73. Wang X, Osinska H, Dorn GW 2nd, Nieman M, Lorenz JN, Gerdes AM, Witt S, Kimball T, Gulick J, Robbins J. Mouse model of desmin-related cardiomyopathy. Circulation. 2001; 103:2402-2407. [PubMed: 11352891]

74. Wang X, Osinska H, Klevitsky R, Gerdes AM, Nieman M, Lorenz J, Hewett T, Robbins J. Expression of R120G-alphaB-crystallin causes aberrant desmin and alphaB-crystallin aggregation and cardiomyopathy in mice. Circ Res. 2001; 89:84-91. [PubMed: 11440982]

75. Wang X, Klevitsky R, Huang W, Glasford J, Li F, Robbins J. AlphaB-crystallin modulates protein aggregation of abnormal desmin. Circ Res. 2003; 93:998-1005. [PubMed: 14576194]

76. Decker RS, Wildenthal K. Lysosomal alterations in hypoxic and reoxygenated hearts. I. Ultrastructural and cytochemical changes. Am J Pathol. 1980; 98:425-444. [PubMed: 7355988]

77. Elmore SP, Qian T, Grissom SF, Lemasters JJ. The mitochondrial permeability transition initiates autophagy in rat hepatocytes. FASEB J. 2001; 15:2286-2287. [PubMed: 11511528]

78. Nowikovsky K, Reipert S, Devenish RJ, Schweyen RJ. Mdm38 protein depletion causes loss of mitochondrial $\mathrm{K}+\mathrm{H}+$ exchange activity, osmotic swelling and mitophagy. Cell Death Differ. 2007; 14:1647-1656. [PubMed: 17541427]

79. Priault M, Salin B, Schaeffer J, Vallette FM, di Rago JP, Martinou JC. Impairing the bioenergetic status and the biogenesis of mitochondria triggers mitophagy in yeast. Cell Death Differ. 2005; 12:1613-1621. [PubMed: 15947785]

80. Twig G, Elorza A, Molina AJ, Mohamed H, Wikstrom JD, Walzer G, Stiles L, Haigh SE, Katz S, Las G, Alroy J, Wu M, Py BF, Yuan J, Deeney JT, Corkey BE, Shirihai OS. Fission and selective fusion govern mitochondrial segregation and elimination by autophagy. EMBO J. 2008; 27:433446. [PubMed: 18200046]

81. Carreira RS, Lee Y, Ghochani M, Gustafsson AB, Gottlieb RA. Cyclophilin D is required for mitochondrial removal by autophagy in cardiac cells. Autophagy. 2010; 6

82. Narendra D, Tanaka A, Suen DF, Youle RJ. Parkin is recruited selectively to impaired mitochondria and promotes their autophagy. J Cell Biol. 2008; 183:795-803. [PubMed: 19029340]

83. Weiss JN, Korge P, Honda HM, Ping P. Role of the mitochondrial permeability transition in myocardial disease. Circ Res. 2003; 93:292-301. [PubMed: 12933700]

84. Crompton M. The mitochondrial permeability transition pore and its role in cell death. Biochem J. 1999; 341(Pt 2):233-249. [PubMed: 10393078]

85. Xue L, Fletcher GC, Tolkovsky AM. Autophagy is activated by apoptotic signalling in sympathetic neurons: an alternative mechanism of death execution. Mol Cell Neurosci. 1999; 14:180-198. [PubMed: 10576889]

86. Xue L, Fletcher GC, Tolkovsky AM. Mitochondria are selectively eliminated from eukaryotic cells after blockade of caspases during apoptosis. Curr Biol. 2001; 11:361-365. [PubMed: 11267874]

87. Gottlieb RA, Carreira RS. Autophagy in health and disease. 5. Mitophagy as a way of life. Am J Physiol Cell Physiol. 2010; 299:C203-210. [PubMed: 20357180]

88. van Bilsen M, Smeets PJ, Gilde AJ, van der Vusse GJ. Metabolic remodelling of the failing heart: the cardiac burn-out syndrome? Cardiovasc Res. 2004; 61:218-226. [PubMed: 14736538]

89. Stanley WC, Chandler MP. Energy metabolism in the normal and failing heart: potential for therapeutic interventions. Heart Fail Rev. 2002; 7:115-130. [PubMed: 11988636]

90. Lee Y, Lee HY, Gustafsson AB. Regulation of autophagy by metabolic and stress signaling pathways in the heart. J Cardiovasc Pharmacol. 2012; 60:118-124. [PubMed: 22472907]

91. Horowitz JD, Chirkov YY, Kennedy JA, Sverdlov AL. Modulation of myocardial metabolism: an emerging therapeutic principle. Curr Opin Cardiol. 2010; 25:329-334. [PubMed: 20535068]

92. Beer M, Seyfarth T, Sandstede J, Landschutz W, Lipke C, Kostler H, von Kienlin M, Harre K, Hahn D, Neubauer S. Absolute concentrations of high-energy phosphate metabolites in normal, hypertrophied, and failing human myocardium measured noninvasively with (31)P-SLOOP magnetic resonance spectroscopy. J Am Coll Cardiol. 2002; 40:1267-1274. [PubMed: 12383574]

93. Hill JA, Olson EN. Cardiac plasticity. N Engl J Med. 2008; 358:1370-1380. [PubMed: 18367740]

94. Tsukamoto O, Minamino T, Okada K, Shintani Y, Takashima S, Kato H, Liao Y, Okazaki H, Asai M, Hirata A, Fujita M, Asano Y, Yamazaki S, Asanuma H, Hori M, Kitakaze M. Depression of proteasome activities during the progression of cardiac dysfunction in pressure-overloaded heart of mice. Biochem Biophys Res Commun. 2006; 340:1125-1133. [PubMed: 16403436] 
95. Wang ZV, Ferdous A, Hill JA. Cardiomyocyte autophagy: metabolic profit and loss. Heart Fail Rev. 2012

96. Matsui Y, Takagi H, Qu X, Abdellatif M, Sakoda H, Asano T, Levine B, Sadoshima J. Distinct roles of autophagy in the heart during ischemia and reperfusion: roles of AMP-activated protein kinase and Beclin 1 in mediating autophagy. Circ Res. 2007; 100:914-922. [PubMed: 17332429]

97. Zhu H, Tannous P, Johnstone JL, Kong Y, Shelton JM, Richardson JA, Le V, Levine B, Rothermel BA, Hill JA. Cardiac autophagy is a maladaptive response to hemodynamic stress. J Clin Invest. 2007; 117:1782-1793. [PubMed: 17607355]

98. Cao DJ, Wang ZV, Battiprolu PK, Jiang N, Morales CR, Kong Y, Rothermel BA, Gillette TG, Hill JA. Histone deacetylase (HDAC) inhibitors attenuate cardiac hypertrophy by suppressing autophagy. Proc Natl Acad Sci U S A. 2011; 108:4123-4128. [PubMed: 21367693]

99. Sinha S, Levine B. The autophagy effector Beclin 1: a novel BH3-only protein. Oncogene. 2008; 27(1):S137-148. [PubMed: 19641499]

100. Rifki OF, Hill JA. Cardiac autophagy: good with the bad. J Cardiovasc Pharmacol. 2012; 60:248252. [PubMed: 22743635]

\section{Non-standard abbreviations and Acronyms}

Atg

BAG2

Bnip

CHIP

GSK3beta

HSC70

HSP70

HSPB8

LAMP2A

UPS autophagy

Bcl2-associated athanogene 2

$\mathrm{Bcl} 2$ and adenovirus E1B $19 \mathrm{kDa}$-interacting protein 3

carboxyl terminus of HSP70-interacting protein

glycogen synthase kinase 3 beta

heat shock cognate $70 \mathrm{kD}$ protein

heat shock protein 70

heat shock protein beta 8

lysosomal-associated membrane protein $2 \mathrm{~A}$

ubiquitin proteasome system 

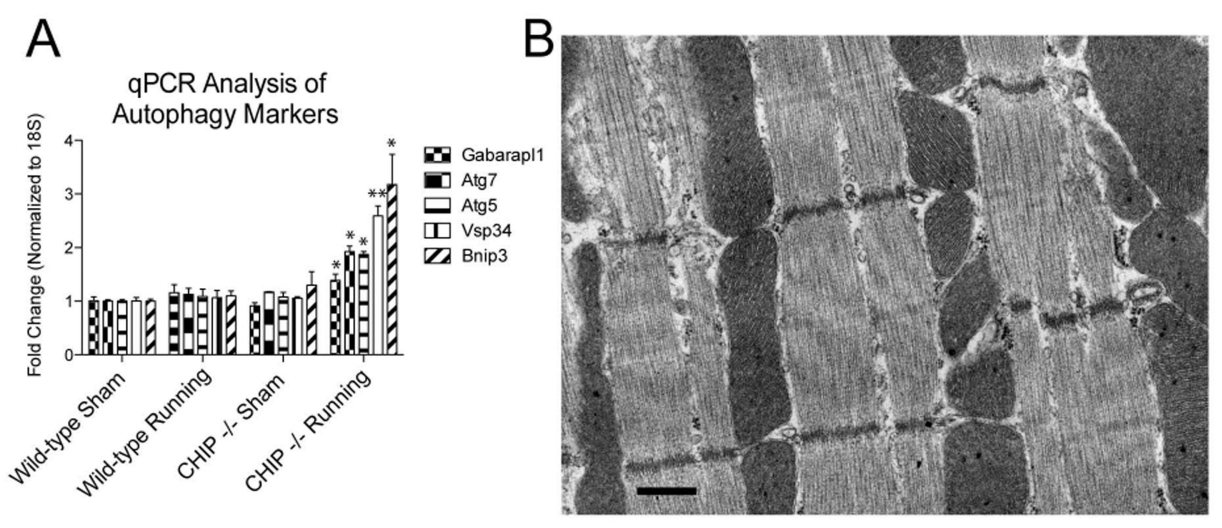

C
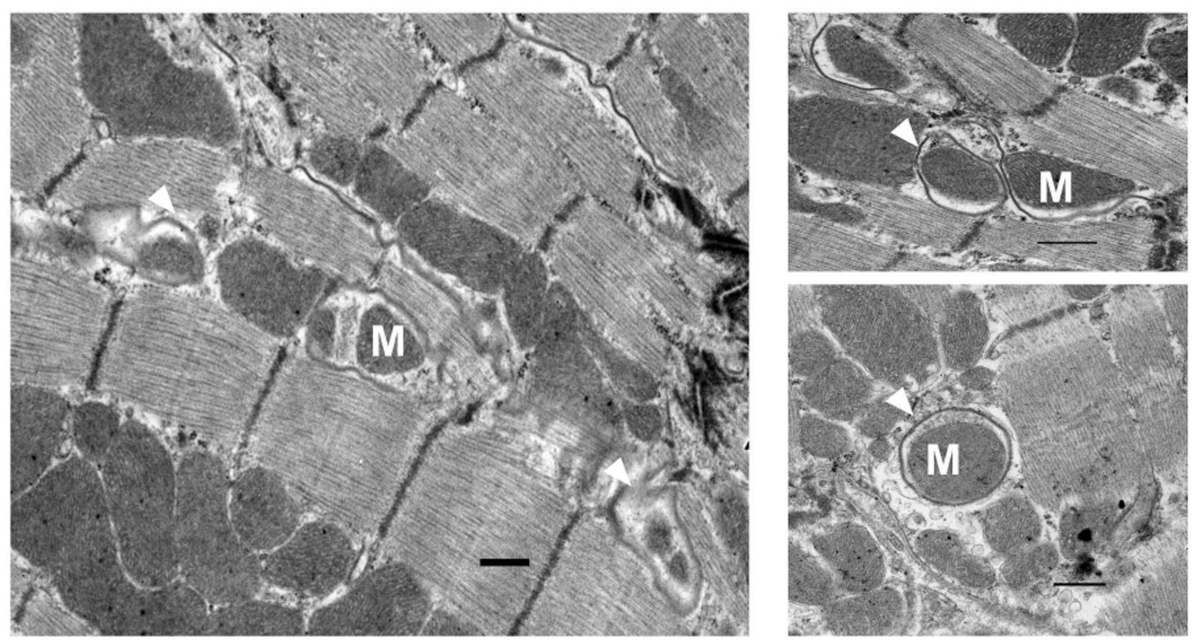

Figure 1. Enhanced autophagic process after voluntary exercise in CHIP-/- mouse

A. Quantitative real-time PCR analysis for indicated genes involved in autophagic process. $* \mathrm{p}<0.05 ; *$; $<0.01$ versus CON group. B. Representative TEM from CHIP $+/+$ and C. CHIP -/- heart in RUN groups. M, mitochondria; white arrow head, autophagosomes containing mitochondria. Data represent means \pm SEM. Scale bar in each panel indicates $0.5 \mu \mathrm{m}$. 

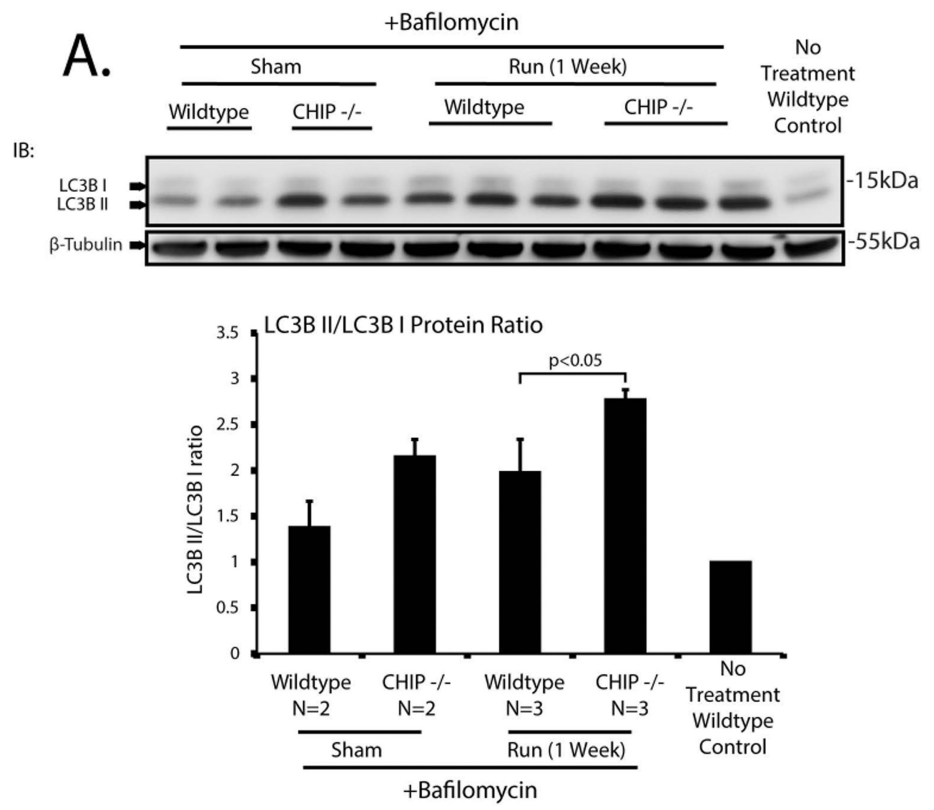

B.
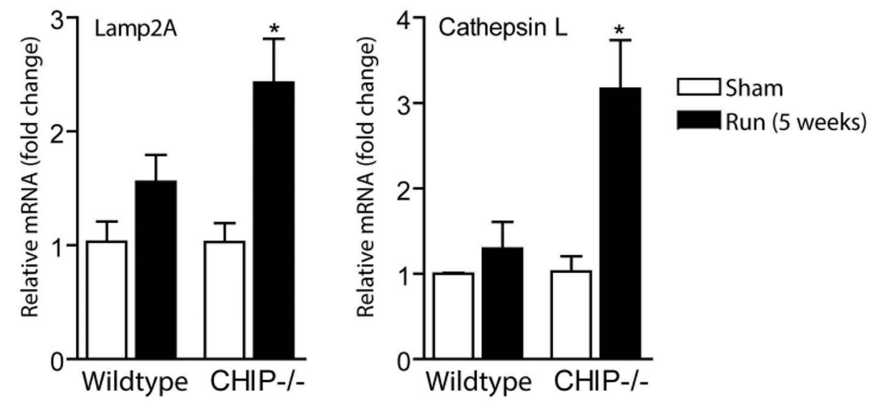

Figure 2. CHIP-/- hearts have enhanced autophagic flux and lysosomal gene expression after voluntary exercise

A. CHIP -/- hearts have an enhanced LC3B II expression after 1 week of voluntary running compared to wild type controls ( $\mathrm{N}=3$ /group). B. Quantitative real time PCR analysis for Lamp2a and Cathepsin L genes. Relative mRNA expression of indicated genes in RUN group (R) is normalized to CON group (C) of each genotype. 3-4 animals per each group were used for RT-PCR analysis. Data represent means \pm SEM. ${ }^{*} \mathrm{p}<0.05$ versus genotype matched sham group. 

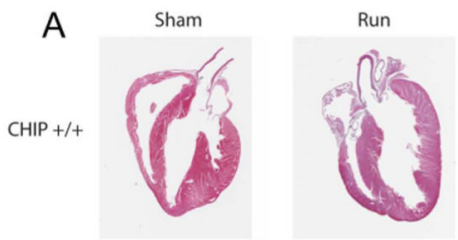

B
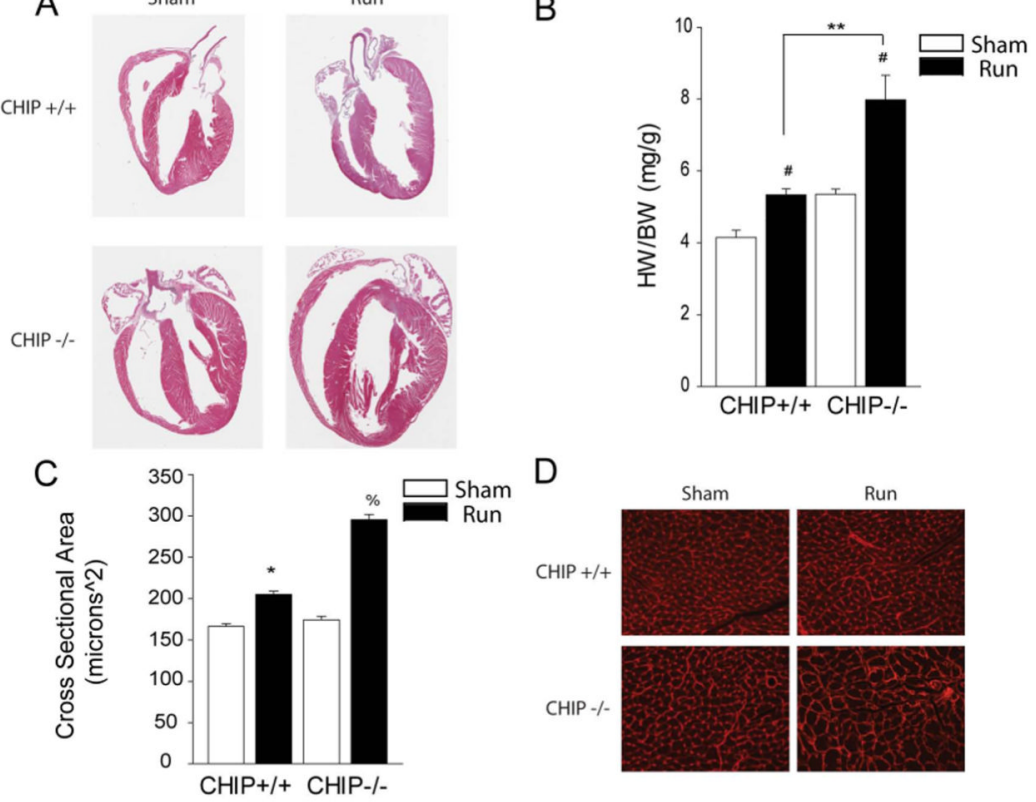

E
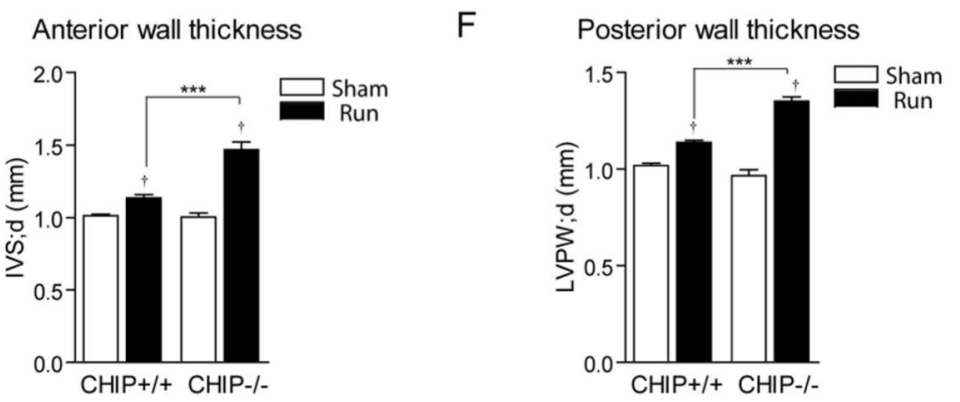

Figure 3. Exaggerated cardiac hypertrophy in CHIP-/- mouse after voluntary exercise A. Representative H\&E stained heart section showing thicker left ventricle in CHIP-/mouse from running (RUN) groups. B. Heart weight (HW) to body weight (BW) ratio in $\mathrm{CHIP}+/+$ and $\mathrm{CHP}-/-$ mouse from CON (C) and RUN (R) groups. \#, $P<0.05$ verses each CON group; **, $P<0.01$ C. Quantification of cross sectional area (CSA) measured in lectinstained heart section from each group. Hearts from 3 to 6 mice were used and more than 200 cardiomyocytes per heart were counted. * $\mathrm{p}<0.05$. D. Representative lectin stained heart section from CHIP+/+ and CHIP-/- mouse in CON and RUN group. $\mathbf{E} \& \mathbf{F}$. Anterior wall (E, IVS;d) and Posterior wall (F, LVPW;d) thickness obtained from echocardiography. Data represent means \pm SEM. $\dagger \mathrm{p}<0.001$ verses each CON group; $* * * \mathrm{p}<0.001$ verses each CON group; \% p $<0.001$ vs. CHIP $-/-$ Running; * vs. $\mathrm{p}<0.001$ vs. CHIP +/+ Running. 


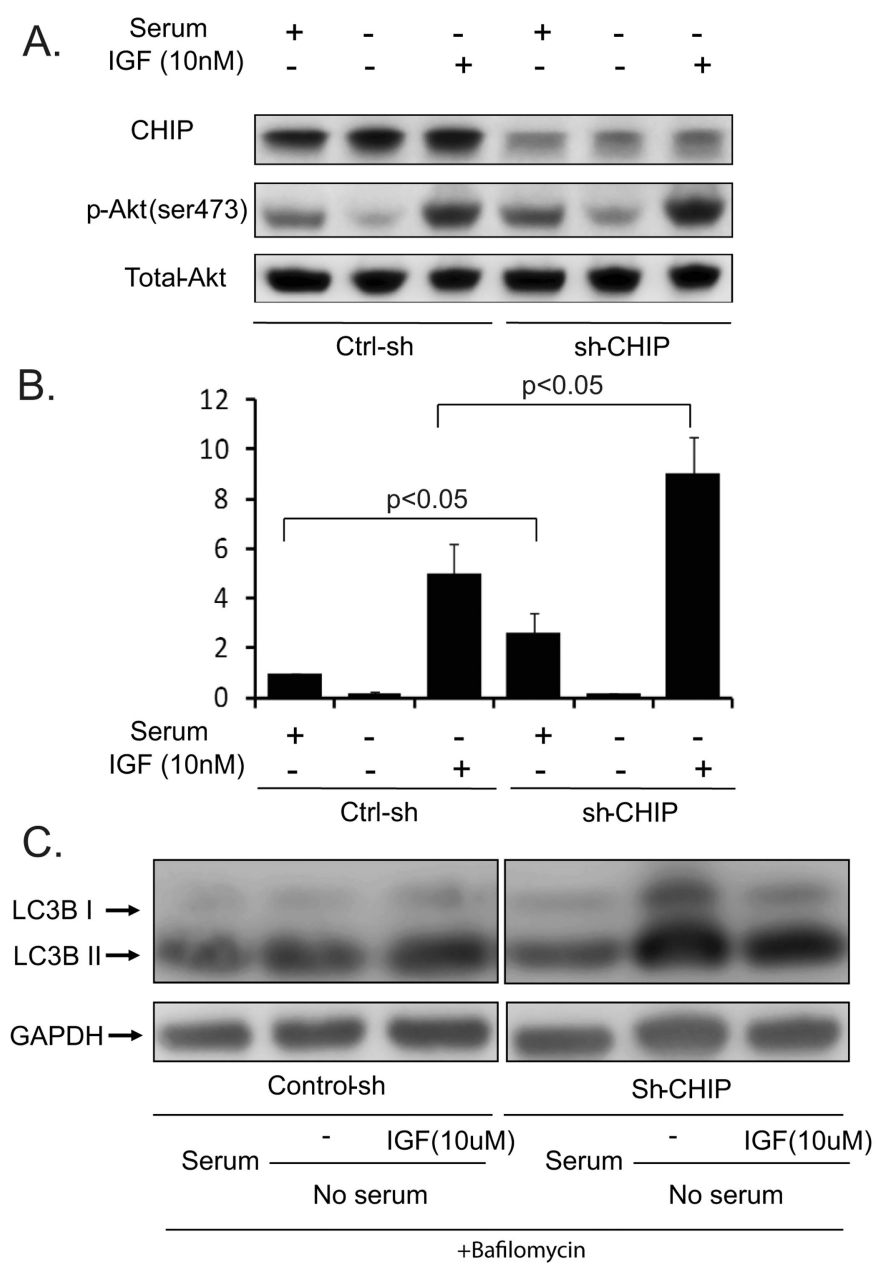

Figure 4. Knockdown CHIP augments IGF induced Akt signaling and enhanced autophagy in HL-1 cardiac-derived cells

A. HL-1 cells with stable CHIP knockdown HL-1 cells (sh-CHIP), or control (Ctrl-sh) were treated with $10 \mathrm{ng} / \mathrm{ml} \mathrm{IGF-1} \mathrm{for} 30$ minutes. Western analysis of CHIP, phospho-Akt and total Akt were then performed and B. quantitatively and statistically analyzed (mean+_ S.D, $\mathrm{n}=3$ in each group) $\mathbf{C}$. Stable CHIP knockdown HL-1 cells (shRNA CHIP=sh-CHIP) and control HL-1 cells (shRNA CHIP=Ctrl-sh) were treated with $10 \mathrm{ng} / \mathrm{ml} \mathrm{IGF-1} \mathrm{for} 4$ hours levels of autophagy were determined by Western blot of LC3B isoforms (blots represent the results of 2 independent experiments). Data represent means \pm SEM. 
A
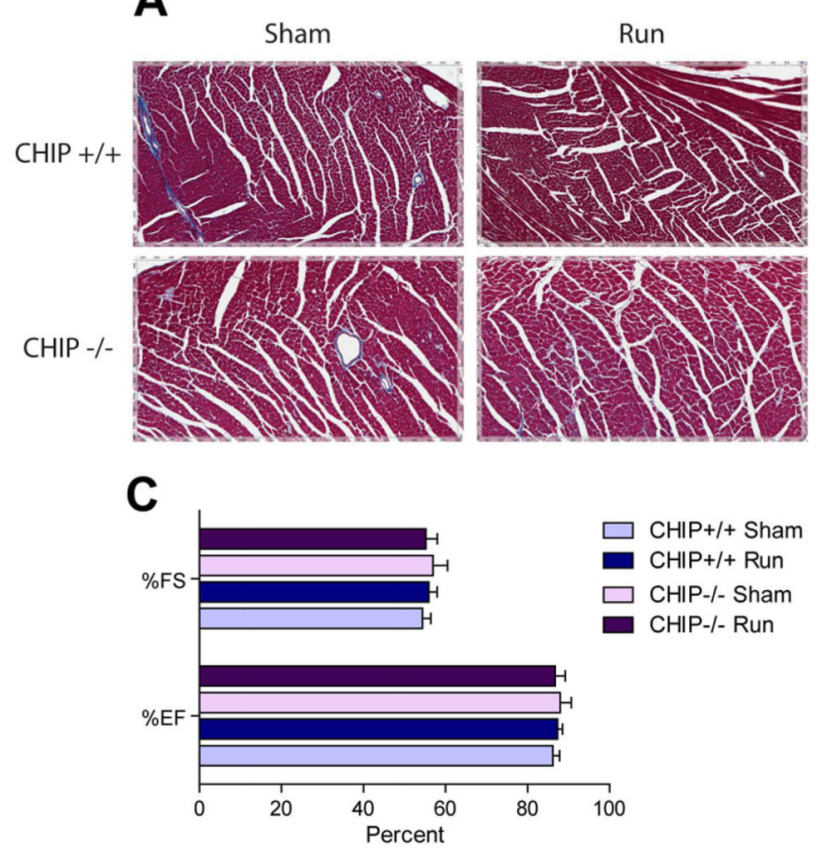

B

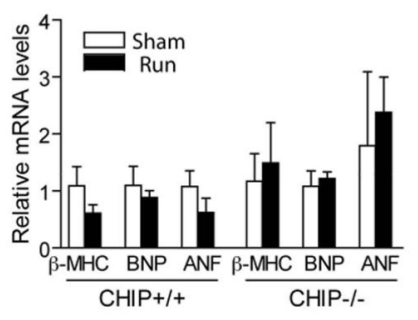

Figure 5. CHIP-/- hearts do not show characteristics of pathological cardiac hypertrophy after exercise

A. Analysis of representative heart sections of wild-type and CHIP -/- left ventricle in sham and running groups stained with Mason's Trichrome (10× magnification; scale surrounding each photomicrograph). B. Quantitative real-time PCR analysis for cardiac fetal genes ( $\beta \mathrm{MHC}, \mathrm{ANF}, \mathrm{BNP}$ ) showing relative mRNA levels of indicated genes in heart from RUN group compared to CON group were not significantly changed in both genotypes. At least 3 animals were used in each group. C. Fractional shortening (\% FS) and ejection fraction (\% EF) calculated from data on echocardiography of mice from indicated groups (detailed data shown in Table 2). Data represent means \pm SEM. 


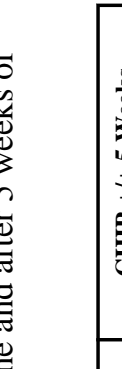

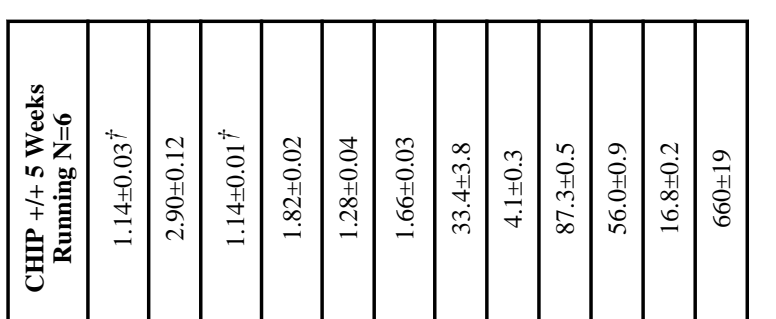

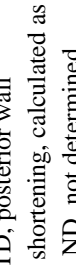

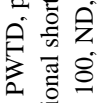

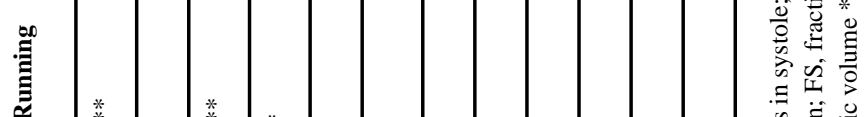

考

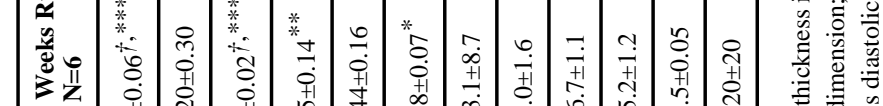

$\sum_{0}^{0}$

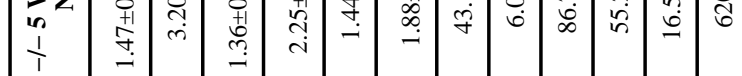

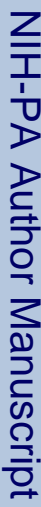

西

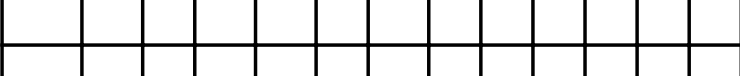

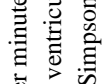

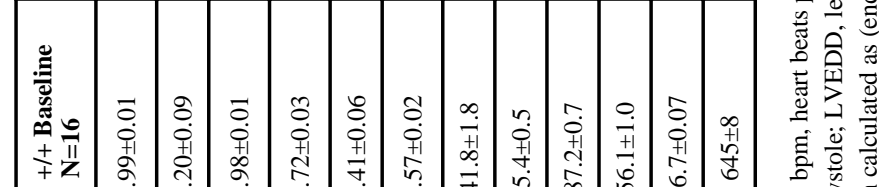

夏

离悹

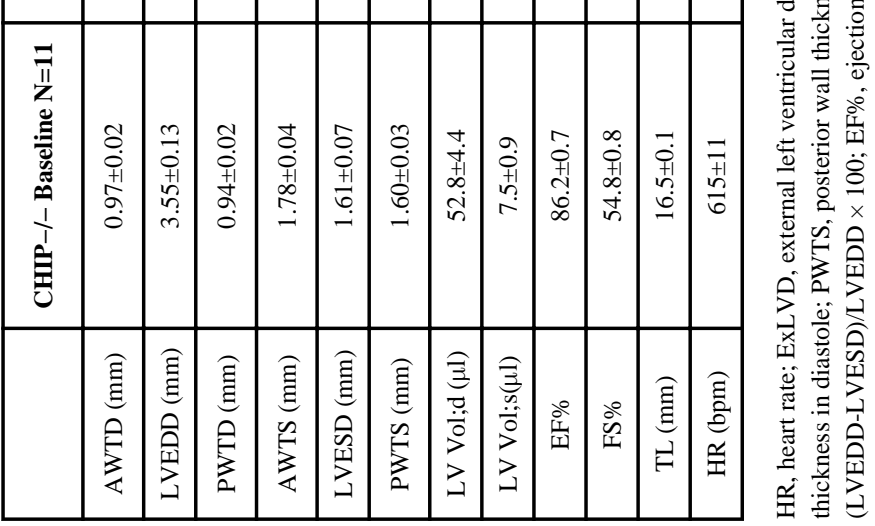

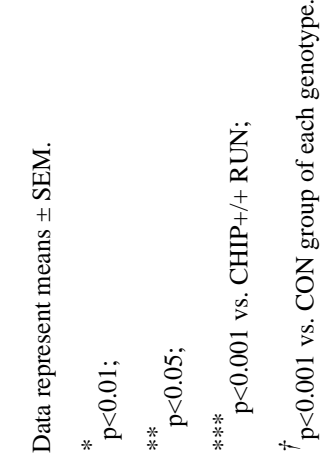

